ISSN 1518-3483

Licenciado sob uma Licença Creative Commons

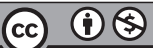

\title{
Representações sociais de ingressantes de Pedagogia sobre creche e pré-escola: um estudo em quatro Estados brasileiros
}

\author{
Social representations of Pedagogy first year students \\ about daycare center and preschool: a study in four \\ Brazilian states
}

\section{Lenira Haddad $^{[a]}$, Maria Helena Cordeiro ${ }^{[b]}$}

[a] Doutora em Educação, professora adjunta da Universidade Federal de Alagoas, Maceió, AL, Brasil, e-mail: lenirahaddad@uol.com.br

[b] Doutora em Psicologia do Desenvolvimento e da Aprendizagem, professora adjunta da Universidade Federal da Fronteira Sul, Chapecó, SC, Brasil, e-mail: mhcordeiro@uffs.edu.br

\section{Resumo}

A educação infantil engloba dois tipos de atendimento que se desenvolveram paralelamente, firmados em distintas tradições, identidades e inserções administrativas. No Brasil, a LDB/96 redefine creche e pré-escola de forma a diferenciá-las apenas quanto à faixa etária atendida ( 0 a 3 anos e 4 a 5 anos, respectivamente), atribuindo a ambas as ações de cuidar e educar, em período parcial ou integral. No entanto, essa compreensão de suas funções não é partilhada no senso comum, o que perpetua a cisão da educação 
infantil, aproximando educação e escolarização, de um lado, e cuidado e custódia, do outro. Assim, buscamos na Teoria das Representações Sociais de Moscovici as ferramentas teórico-metodológicas para a compreensão do senso comum sobre a creche e a pré-escola. Participaram desta pesquisa 368 estudantes ingressantes nos cursos de Pedagogia de quatro universidades de quatro Estados brasileiros: 194 da UFAL (Alagoas); 67 da UFMT (Mato Grosso); 68 da Unesp (Presidente Prudente, SP) e 39 da UFMS (Mato Grosso do Sul). Este artigo aborda os resultados encontrados com a técnica de associação livre das palavras creche e pré-escola e das questões fechadas de um questionário que comparavam essas etapas da educação infantil. Para a grande maioria dos sujeitos investigados, creche e pré-escola são diferentes, mas não no sentido dado oficialmente e sim pelas funções tradicionalmente atribuídas a essas instituições, confirmando que elas exercem uma função organizadora das RS sobre o trabalho da professora de El, afetando as imagens que as acadêmicas constroem sobre o trabalho desse profissional.

Palavras-chave: Representações sociais. Creche. Pré-escola. Educação infantil.

\section{Abstract}

The early childhood education encompasses two types of childcare that developed in parallel, forged in different traditions, identities and administrative inserts. In Brazil, LDB/96 redefines daycare center and preschool in order to differentiate themselves only in terms of the age they attend (0-3 years and 4-5 years respectively), assigning to both actions like caring and educating, on full or part-time. However, this understanding of their functions is not shared by common sense, which perpetuates the division of early childhood education, bringing closer education and schooling, on one hand, and care and custody, on the other. Thus, we sought in Moscovici's Theory of Social Representations the theoretical and methodological tools for understanding the common sense about daycare center and preschool. 365 Pedagogy freshmen students took part in this research from four universities of four Brazilian states: 194 from UFAL (Alagoas), 67 from UFMT (Mato Grosso), 68 from Unesp (Presidente Prudente, SP) and 39 from UFMS (Mato Grosso do Sul). This article discusses the results found by the use of the technique of free association of the words daycare and preschool and by the closed questions of a questionnaire that compared these stages of early childhood education. For the major majority of the research subjects, daycare center and preschool are different, not in the same way understood officially, but by the functions 
traditionally assigned to these institutions, confirming that they exert an organizing function of the SR on the work of the early childhood education teacher, affecting the images that the students build about the work of this professional.

Keywords: Social representations. Daycare center. Preschool. Early childhood education.

\section{Introdução}

A educação infantil, que se expressa pelo atendimento à criança de 0 a 5 anos em creches e pré-escolas, constitui, na própria reunião dessas duas vertentes, um objeto polimorfo que se cristaliza em pelo menos dois sentidos fundamentais distintos e até antagônicos.

De um lado, as creches se originam no âmbito de programas sociais e filantrópicos de proteção e prevenção ao abandono e à delinquência e se voltam ao atendimento de crianças e famílias em condições de vulnerabilidade por pobreza, doença, invalidez ou desempenho. A evolução desse tipo de atendimento vincula-se, posteriormente, ao trabalho e à história da mulher trabalhadora. Sua expansão, a partir do fim da década de 70, deve-se, em grande parte, aos movimentos sociais de luta por creches, que estabelecem interfaces com o movimento feminista. Em função desse caráter lhe são emprestados atributos como assistencialista, substituta do lar, dentre outros. Da mesma forma, lhe são associadas características que conformam um atendimento que se volta ao apoio das famílias com filhos pequenos: período integral, cuidados referentes à alimentação, sono, saúde e higiene.

Do outro lado, o que hoje se denomina pré-escola apresenta uma origem bastante diversa da creche: os modelos de educação para a criança pequena concebidos por importantes educadores, como Oberlin (salles d'asile), Robert Owen (infant school), Froebel (kindergarten) e Montessori (casas del bambini), e que se difundiram por todo o mundo. Com foco na criança, seu desenvolvimento e aprendizagem, esses programas foram-se amoldando ao que se considerava importante para a educação da criança. 
Sua grande expansão no Brasil vincula-se aos programas compensatórios que visavam a cobrir déficits educacionais das crianças e garantir seu sucesso escolar futuro. Dadas essas condições, a pré-escola é facilmente identificada com o início da vida escolar da criança e com a preparação para a etapa posterior de ensino. Inspirando-se no modelo de escola formal, empresta deste atributos vinculados a várias práticas que acaba adotando, tais como: a organização dos espaços com carteiras, mesas e lousa; o agrupamento seriado das crianças; a divisão do tempo em disciplinas, com predomínio dos exercícios gráficos; a ênfase no ensino da leitura e escrita e a restrição das atividades lúdicas ao "recreio".

Portanto, creche e pré-escola são programas que se fundam em bases ideológicas distintas e refletem diferentes expectativas quanto aos objetivos, à função, à estrutura de funcionamento e às orientações da prática educativa.

A legalização da educação da criança pequena com a Constituição Federal de 1988 (BRASIL, 1988) anuncia uma nova era para esse campo profissional. Se antes o cuidado e a educação da criança eram tidos como responsabilidade exclusiva da família, o direito à educação desde o nascimento pressupõe a responsabilidade social sobre a criança e a legitimação do cuidado e da educação infantil fora do lar, em ação complementar à da família. Contudo, essa concepção, implícita na Constituição brasileira, está ainda no plano ideal e não no campo concreto das práticas sociais.

A LDBEN aprovada em 1996 introduz outras inovações: define a educação infantil como primeira etapa da educação básica; redefine os termos creche e pré-escola, de modo a diferenciar o atendimento segundo duas faixas de idade (creche, para crianças até 3 anos, e pré-escola para as de 4 a 5); e exige a vinculação de todas as instituições ao sistema de ensino. Porém, sua implementação não é acompanhada de uma profunda revisão nos objetivos e funções de ambas as instituições, de forma a superar as inconsistências do passado.

O argumento que defendemos neste artigo é que, ao contrário do que se supõe, não é a legitimidade legal da educação infantil ante os sistemas de ensino que vai garantir a ruptura das polaridades tradicionalmente 
marcadas pelo foco custodial e o enfoque propedêutico. Isso porque o sistema de educação, e aí incluímos os cursos de formação de professores, não tem tradição de considerar aspectos que vão além da dimensão ensinoaprendizagem escolar. Um conjunto de ações é necessário para romper as barreiras impostas pelo passado, dentre elas a compreensão das forças que atuam na manutenção dessas barreiras.

Neste artigo, assumimos a visão de sistema integrado de educação e cuidado, conforme defendido por Haddad em trabalhos anteriores (1997, 2002 e 2006). Nessa visão, um sistema que integra e unifica creches e pré-escolas, cuidado e educação decorre da mudança de paradigma, em que a responsabilidade pelo cuidado e pela socialização da criança pequena deixa de ser exclusiva da família para ser compartilhada por toda a sociedade. Trata-se, assim, da transição de um modelo de déficit (baseado na falta da família) para um modelo de partilha (baseado nos direitos humanos).

Essa visão coloca em primeiro plano as mudanças de atitudes relativas ao papel do Estado e da sociedade no que diz respeito à educação, cuidado e socialização das crianças. Essas mudanças levam a uma definição mais ampla de educação e cuidado que inclui o direito da família de dividir com a sociedade o cuidado e a educação da criança e o direito da criança de ser cuidada e socializada em um contexto social mais amplo que o da família, considerando as múltiplas possibilidades de interações que este ambiente oferece.

$\mathrm{Na}$ perspectiva de uma abordagem integrada, um novo elemento se interpõe ao cuidado e à educação - a legitimação da socialização infantil extrafamiliar - e funciona como elo entre eles, alterando seus significados. A ideia é que a ausência dessa legitimação causa ruptura no todo, resultando em sistemas paralelos e na descontinuidade dos serviços. Essa ruptura acarreta mudança de significados associados ao conceito de cuidado e educação, mediante a aproximação entre educação e escolarização, privilegiando as crianças mais velhas, e entre cuidado e custódia, focalizando as famílias e as crianças em situações de risco ou com necessidades especiais de apoio. A consequência é o obscurecimento do conceito de educação.

Nesse contexto, a dimensão conceitual da educação infantil torna-a presa fácil de manipulação ideológica e a difícil compreensão das suas 
especificidades fragiliza as conquistas do campo. Vulnerável, fica à mercê do senso comum. Por isso, tanto na formação de professores como na luta por políticas públicas que reconheçam e respeitem essas especificidades é importante considerar quais são as ideias do senso comum que perpetuam as cisões e impedem a adoção de uma abordagem integrada no atendimento à criança de 0 a 5 anos.

Assim, buscamos na Teoria das Representações Sociais (MOSCOVICI, 2005) as ferramentas teórico-metodológicas para a compreensão do senso comum sobre a educação infantil, mais especificamente sobre a creche e a pré-escola.

De acordo com Abric (2000), as representações sociais possuem uma estrutura em que se pode distinguir um núcleo central e um sistema periférico. O primeiro é constituído pelos elementos mais permanentes e cristalizados e que dão sentido à representação. Assim, a centralidade de um elemento é determinada pelo sentido que ele atribui à representação. Associados aos elementos centrais, agregam-se outros, mais variáveis, que estabelecem a ligação entre os primeiros e a realidade, protegendo o núcleo e dando concretude à representação.

Essa estrutura permite que a representação desempenhe várias funções: definição da realidade dos objetos; proteção da identidade de grupos; comunicação; orientação. Apesar do aumento de pesquisas ${ }^{1}$ que utilizam da TRS para investigar aspectos específicos da educação infantil, pouca atenção tem sido dada ao poder da dimensão normativa na condução de atitudes e práticas neste campo.

O conceito de norma numa abordagem sociocognitiva tem sido explorado por diversos pesquisadores da escola de Aix-en-Provence (dentre eles Abric, Flament, Guimelli, Moliner), que postulam a existência de aspectos normativos nas representações sociais ao lado de outros aspectos mais práticos ou funcionais, ou, ainda, descritivos (MENIN, 2007).

1 Ver SALES, 2007; PACHECO, 2005; ONGARI; MOLINA, 2003; FERNANDES, 2004; DEMATHÉ, 2007, dentre outros. 
Para Abric, (1987, p. 119) citado por Menin (2007), a função normativa de uma representação é guardar o significado que o objeto representado deve ter. Essa dimensão normativa seria suscetível de privilegiar os julgamentos, estereótipos e opiniões admitidos pelo sujeito ou grupo social no qual ele se insere e explica a resistência à mudança que impõe às representações.

Do ponto de vista da Teoria das Representações Sociais (MOSCOVICI, 2005), defendemos neste trabalho que a educação infantil apresenta uma natureza controversa. Por constituir-se em um espaço infantil coletivo não familiar de cuidado e educação, ela é um objeto de tensão normativa, apresentando defasagem entre as normas legais (o que deve ser, porque assim diz a lei) e as normas sociais (o que é, conforme a maioria privilegia como ação, pensamento e discurso).

Essa defasagem contribui negativamente para o delineamento da identidade específica do campo profissional e, consequentemente, da identidade do professor da educação infantil. Como um reflexo das heranças históricas, a caracterização da intencionalidade "educativa" deste professor é ambígua, oscilando de um polo orientado pela instrução e ensino a outro regulado pelo sentido mais amplo da formação da pessoa.

Nessa perspectiva, compreender os significados atribuídos à creche e à pré-escola por acadêmicos do curso de Pedagogia de quatro universidades brasileiras pode nos auxiliar a refletir se, no imaginário desses ingressantes e futuros professores, o campo da educação infantil continua cindido em distintas naturezas, funções e práticas ou se já se aproxima das novas conceituações em curso. Além disso, investigar o conceito de criança e de professor associados a cada uma dessas subetapas da educação infantil pode nos dar a dimensão de modelo profissional que se configura em torno da figura do(a) professor(a) de educação infantil na visão de futuros professores.

\section{A pesquisa}

Este artigo refere-se a um pequeno recorte de uma pesquisa longitudinal na qual se pretende acompanhar os estudantes durante toda a 
sua formação na universidade, por quatro anos, de seu ingresso à conclusão do curso de graduação. O estudo prevê três etapas. Na primeira, os acadêmicos ingressantes nos cursos de Pedagogia respondem a um questionário em forma de carta que inclui algumas questões de associação livre. A segunda etapa é um aprofundamento da análise dos sentidos atribuídos às palavras mais evocadas a partir de uma entrevista feita com uma amostra dos sujeitos que participaram da primeira etapa. A terceira etapa refere-se à análise da trajetória dos alunos nos cursos de formação.

Aqui será apresentada apenas a análise de parte dos dados gerados na primeira etapa. A coleta de dados desta etapa teve início no segundo semestre de 2008. Realizado inicialmente com os estudantes do curso de Pedagogia da UFAL, ingressantes nos anos de 2008 e 2009, o projeto foi expandido a mais três universidades durante o ano de 2009, UFMT, Unesp (câmpus de Presidente Prudente) e UFMS (Corumbá). Os sujeitos participantes da pesquisa $(n=368)$ estão assim distribuídos: UFAL, 194; Unesp/PPTE, 68; UFMS/Corumbá, 39; UFMT, 67.

Para a realização da primeira etapa foi necessário desenvolver instrumentos que considerassem as especificidades da educação infantil, processo que envolveu uma série de desafios teórico-metodológicos que são apresentados em Cordeiro e Haddad (2011). Esses instrumentos incluíram um questionário para o levantamento do perfil sociodemográfico e profissional dos sujeitos e um questionário em forma de carta, relativo ao trabalho do professor da educação infantil. Além disso, foi também utilizada a técnica de associação livre, tendo como palavras indutoras: creche, pré-escola, criança e professor. O tratamento dos dados obtidos com esta técnica foi realizado com o auxílio do software EVOC ${ }^{\circledR}$ (VERGÈS, 2000), que permite formular hipóteses acerca do conteúdo e da estrutura da representação com base na frequência ( $F)$, na ordem média da evocação (OME) e também na importância atribuída pelos sujeitos às palavras por eles evocadas espontaneamente.

Para efeito deste artigo, discutiremos os dados referentes às palavras creche e pré-escola, evocadas no teste de associação livre, e as respostas às questões fechadas do questionário que abordavam os fatores de diferenciação entre professor de creche e de pré-escola. 


\section{Apresentação e discussão dos resultados}

A grande maioria dos sujeitos participantes da pesquisa é do sexo feminino (94, 4\%), com idade concentrada entre 17 e 25 anos, solteira $(78 \%)$ e sem filhos. Quando considerada individualmente, a UFMT é uma exceção, pois a maioria dos sujeitos (52\%) tem mais de 25 anos e cerca de metade é casada ou divorciada e tem filhos. O número de sujeitos cujos pais têm apenas o ensino fundamental ou são analfabetos é alto e de forma geral a escolaridade das mães é superior à dos pais. Os dados também revelam que, em todas as IES, a maioria das estudantes constitui a primeira geração a ingressar na universidade e, em muitos casos, esta é também a primeira geração a terminar o ensino médio.

A análise produzida pelo EVOC $^{\circledR}$ com base nas evocações induzidas pela palavra creche é mostrada na Tabela 1 .

Tabela 1 - Lista das palavras mais frequentemente evocadas diante do estímulo indutor creche, com as respectivas frequências, ordens médias de evocação e frequência com que as palavras foram destacadas como mais importantes

(Continua)

\begin{tabular}{|c|c|c|c|c|c|c|c|}
\hline \multicolumn{8}{|c|}{ Creche } \\
\hline $\begin{array}{l}\text { Núcleo } \\
\text { central }\end{array}$ & $F=>60$ & $\begin{array}{c}\text { OME } \\
<2,49\end{array}$ & $\mathrm{Fi}$ & Primeira periferia & $F=>60$ & $\begin{array}{c}\text { OME } \\
>=2,49\end{array}$ & $\mathrm{Fi}$ \\
\hline \multirow[t]{5}{*}{ criança } & 341 & 1,07 & 243 & cuidado & 95 & 2,79 & 14 \\
\hline & & & & brincar-brincadeira & 89 & 2,87 & \\
\hline & & & & professor-professora & 87 & 2,79 & 8 \\
\hline & & & & educação & 79 & 2,71 & 18 \\
\hline & & & & brinquedo & 60 & 2,77 & 1 \\
\hline $\begin{array}{l}\text { Zona de } \\
\text { contraste }\end{array}$ & $F<60$ & $\begin{array}{c}\text { OME } \\
<2,49\end{array}$ & $\mathrm{Fi}$ & Segunda periferia & $F<60$ & $\begin{array}{c}\text { OME } \\
>=2,49\end{array}$ & $\mathrm{Fi}$ \\
\hline escola & 19 & 2,26 & & alimentação & 38 & 2,97 & \\
\hline bebê & 12 & 2,08 & & amor & 34 & 3,21 & 5 \\
\hline
\end{tabular}


Tabela 1 - Lista das palavras mais frequentemente evocadas diante do estímulo indutor creche, com as respectivas frequências, ordens médias de evocação e frequência com que as palavras foram destacadas como mais importantes

(Conclusão)

\begin{tabular}{|c|c|c|c|c|c|c|c|}
\hline \multicolumn{8}{|c|}{ Creche } \\
\hline $\begin{array}{l}\text { Zona de } \\
\text { contraste }\end{array}$ & $F<60$ & $\begin{array}{l}\text { OME } \\
<2,49\end{array}$ & $\mathrm{Fi}$ & Segunda periferia & $F<60$ & $\begin{array}{c}\text { OME } \\
>=2,49\end{array}$ & $\mathbf{F i}$ \\
\hline infância & 10 & 2,30 & & ensino-ensinar & 34 & 2,97 & 5 \\
\hline \multirow[t]{14}{*}{ aluno } & 6 & 2,33 & & aprendizagem-aprender & 29 & 2,93 & 6 \\
\hline & & & & proteção & 24 & 3,00 & \\
\hline & & & & $\begin{array}{l}\text { responsabilidade- } \\
\text { responsável }\end{array}$ & 21 & 2,81 & \\
\hline & & & & lazer-diversão & 20 & 3,35 & \\
\hline & & & & choro & 19 & 2,84 & \\
\hline & & & & atenção-atento & 17 & 3,29 & \\
\hline & & & & barulho & 16 & 2,81 & \\
\hline & & & & família & 16 & 3,31 & \\
\hline & & & & bagunça & 14 & 2,64 & \\
\hline & & & & babá & 13 & 2,62 & \\
\hline & & & & berçário & 13 & 2,92 & \\
\hline & & & & educador & 13 & 3,23 & \\
\hline & & & & mãe & 11 & 3,18 & \\
\hline & & & & alegre-alegria & 10 & 3,00 & \\
\hline
\end{tabular}

Fonte: Dados da pesquisa.

Na tabela é possível observar que apenas a palavra criança aparece no primeiro quadrante, com uma frequência de 341 evocações, ou seja, foi mencionada por cerca de $93 \%$ dos sujeitos. Além disso, entre as 341 pessoas que evocaram essa palavra, 243 (ou seja, 71\%) a sinalizaram como sendo a mais importante das quatro evocadas por elas. Há, assim, uma quase unanimidade no que se refere à ideia/imagem de criança como sendo a aglutinadora dos significados da representação social de creche, 
o que sugere que esta é vista como um lugar da criança, ou para a criança, e que, portanto, não pode ser concebida a não ser em função dessa relação. A observação dos outros quadrantes permite compreender melhor a organização dos conteúdos da representação. As palavras evocadas por um grande número de pessoas em sequência ao par creche-criança esclarecem os significados que dão sentido a essa ligação. Assim, podemos distinguir, nas evocações colocadas na primeira periferia (quadrante superior direito), três dimensões: a primeira diz respeito às funções atribuídas à creche e caracterizam-na como um espaço de cuidado $(F=95)$ e de educação $(\mathrm{F}=79)$ da criança. A segunda dimensão esboça os elementos da imagem de criança que dão sentido ao fato de o núcleo central da representação de creche se consolidar nessa imagem: brincar-brincadeira ( $\mathrm{F}=$ 89) e brinquedo $(F=60)$. Temos, então, o delineamento de um lugar de cuidado e educação da criança, cuja natureza se expressa em sua atividade essencial, a brincadeira. Finalmente, a terceira dimensão se refere ao mediador, isto é, à pessoa que proporciona à criança o cuidado e a educação, garantindo o cumprimento das funções atribuídas à creche: o professor (ou, mais provavelmente, a professora) $(\mathrm{F}=87)$. Assim, se a creche é um lugar da criança e, portanto, um lugar de brincadeira, cabe à professora a tarefa de garantir essa função, organizando brincadeiras e brincando com as crianças, o que foi confirmado nas respostas à questão n. 23 do questionário, na qual $85 \%$ das acadêmicas indicaram que essa é a tarefa mais importante da professora da creche.

A segunda periferia (quadrante inferior direito) permite compreender como as diferentes dimensões identificadas na primeira periferia se ancoram nas experiências dos sujeitos, protegendo e fortalecendo o núcleo central da representação. As palavras localizadas neste quadrante mostram como as funções de cuidado e de educação se desdobram em: alimentação, amor e proteção, ensino-ensinar, lazer-diversão e [atendimento à] família.

Essas funções da creche devem ser assumidas com atenção e responsabilidade, por meio de tarefas atribuídas à professora, como mostram as respostas ao questionário. Assim, em resposta à questão 23 , sobre as tarefas da professora da creche, as acadêmicas indicaram, além de brincar 
e organizar brincadeiras (já mencionado): o atendimento a necessidades afetivas (dar carinho - cerca de 75\%), o ensino (observar e avaliar as crianças $-65 \%$, participar de reuniões pedagógicas $-67 \%$ ), a proteção (zelar pela integridade física das crianças - 63\%), além da manutenção do contato com as famílias (78\%). No questionário também foi priorizado o atendimento a crianças com necessidades especiais (70\%), provavelmente porque se tratava de uma questão fechada em que essa era uma das opções. Entretanto, esse conteúdo não foi evocado espontaneamente na questão de associação livre.

É interessante verificar que a maioria dos sujeitos não considerou como tarefa da professora alimentar a criança, assim como outras opções relativas ao atendimento às necessidades básicas, ${ }^{2}$ o que sugere que as acadêmicas não compreendem o caráter educativo dessas tarefas e, provavelmente, pressupõem a existência de outros profissionais na creche para darem conta delas.

A segunda periferia abriga ainda outras palavras referentes às características da criança (choro, barulho, bagunça e alegria), mostrando que a criança da creche é uma criança real, barulhenta e agitada. É intrigante que a evocação alegre-alegria tenha aparecido com uma frequencia tão baixa ( $F=10)$, já que nos estudos sobre a representação social da infância, ou da criança (DEMATHÉ; CORDEIRO, 2009; ANDRADE; SANTOS, 2009), esse atributo é um dos mais frequentes e mais rapidamente evocados. Esse resultado nos leva a questionar se, na concepção das acadêmicas, a criança da/na creche não é uma criança alegre e se esse fato traduz uma velha ideia de que a creche não é o lugar mais adequado para a criança pequena. Essa questão se torna mais pertinente diante de outras palavras pouco frequentes que estão localizadas nesta periferia: babá, berçário, educador e mãe, as quais podem indicar a permanência de tensões entre a ideia de que as crianças pequenas são responsabilidade privada e devem ser cuidadas no espaço doméstico e não no espaço público da creche. As respostas ao questionário confirmam essa concepção doméstica do trabalho da professora de creche, pois a profissão considerada mais próxima foi a de babá (cerca de 60\% das respostas).

2 Alimentar a criança (48\%); dar banho (43\%); trocar fraldas (41\%) dar remédio e fazer curativos (32\%). 
Por fim, as palavras localizadas no quadrante inferior esquerdo constituem a zona de contraste, sugerindo a existência de grupos divergentes e/ou tendências de resistência ou mudança da representação. As palavras escola $(\mathrm{F}=19)$ e aluno $(\mathrm{F}=6)$ mostram a existência de um grupo que identifica a creche com a escola, não considerando as suas especificidades. Por outro lado, a palavra bebê, também pouco frequente $(F=12)$, pode refletir a tensão colocada anteriormente ou o reconhecimento de que a creche se destina aos bem pequenos.

A análise das evocações induzidas pelo estímulo indutor pré-escola é mostrada na Tabela 2 .

Tabela 2 - Lista das palavras mais frequentemente evocadas diante do estímulo indutor pré-escola, com as respectivas frequências, ordens médias de evocação e frequência com que as palavras foram destacadas como mais importantes

(Continua)

\begin{tabular}{|c|c|c|c|c|c|c|c|}
\hline \multicolumn{8}{|c|}{ Pré-escola } \\
\hline Núcleo central & $F=>45$ & $\begin{array}{l}\text { OME } \\
<2,46\end{array}$ & $\mathbf{F i}$ & Primeira periferia & $F=>45$ & $\begin{array}{c}\text { OME } \\
>=2,46\end{array}$ & $\mathrm{Fi}$ \\
\hline criança & 188 & 1,81 & 94 & professor-professora & 104 & 2,59 & \\
\hline $\begin{array}{l}\text { alfabetização- } \\
\text { alfabetizar }\end{array}$ & 102 & 2,15 & 26 & brincar-brincadeira & 70 & 2,97 & \\
\hline $\begin{array}{l}\text { aprendizagem- } \\
\text { aprender }\end{array}$ & 88 & 2,37 & 30 & histórias-artes-jogos & 45 & 2,56 & \\
\hline educação & 75 & 2,09 & 39 & & & & \\
\hline início-base & 62 & 1,98 & 19 & & & & \\
\hline $\begin{array}{l}\text { Zona de } \\
\text { contraste }\end{array}$ & $F<45$ & $\begin{array}{l}\text { OME } \\
<2,46\end{array}$ & $\mathrm{Fi}$ & Segunda periferia & $F<45$ & $\begin{array}{c}\text { OME } \\
>=2,46\end{array}$ & $\mathrm{Fi}$ \\
\hline ensino-ensinar & 41 & 2,17 & 16 & desenvolvimento & 28 & 2,82 & \\
\hline aluno & 26 & 2,04 & 12 & escola & 25 & 2,84 & \\
\hline infância & 23 & 2,04 & 11 & estudo & 23 & 2,48 & \\
\hline conhecimento & 22 & 2,46 & & amigos-amizade & 17 & 2,77 & \\
\hline brinquedo & 12 & 2,25 & & lazer-diversão & 16 & 3,06 & \\
\hline
\end{tabular}


Tabela 2 - Lista das palavras mais frequentemente evocadas diante do estímulo indutor pré-escola, com as respectivas frequências, ordens médias de evocação e frequência com que as palavras foram destacadas como mais importantes

(Conclusão)

\begin{tabular}{|c|c|c|c|c|c|c|c|}
\hline \multicolumn{8}{|c|}{ Pré-escola } \\
\hline $\begin{array}{l}\text { Zona de } \\
\text { contraste }\end{array}$ & $F<45$ & $\begin{array}{c}\text { OME } \\
<2,46\end{array}$ & $\mathrm{Fi}$ & Segunda periferia & $F<45$ & $\begin{array}{c}\text { OME } \\
>=2,46\end{array}$ & $\mathrm{Fi}$ \\
\hline $\begin{array}{l}\text { importante- } \\
\text { necessidade }\end{array}$ & 11 & 2,46 & & amor & 15 & 2,73 & \\
\hline $\begin{array}{l}\text { cadeira-carteira- } \\
\text { mesa }\end{array}$ & 7 & 2,29 & & cuidado & 15 & 2,80 & \\
\hline sala & 7 & 1,57 & & atenção-atento & 14 & 2,57 & \\
\hline didática & 5 & 1,80 & & alegre-alegria & 11 & 3,18 & \\
\hline \multirow[t]{8}{*}{ maternal } & 5 & 2,20 & & bagunça & 11 & 3,00 & \\
\hline & & & & paciência-calma & 11 & 2,82 & \\
\hline & & & & livros & 10 & 2,50 & \\
\hline & & & & atividades & 9 & 3,33 & \\
\hline & & & & disciplina & 9 & 2,78 & \\
\hline & & & & responsabilidade & 9 & 3,00 & \\
\hline & & & & alimentação & 8 & 3,25 & \\
\hline & & & & socialização-sociável & 8 & 3,00 & \\
\hline
\end{tabular}

Fonte: Dados da pesquisa.

A análise das evocações diante da palavra indutora pré-escola revela que, embora criança também seja a palavra mais frequente, ela tem menor saliência do que a que foi observada no caso da palavra indutora creche, pois a frequência é bem menor e a ordem média de evocação é mais alta. Além disso, outras evocações compõem o possível núcleo central da RS de pré-escola, sugerindo que os significados aglutinadores se diversificam. As funções educação e aprendizagem são mais enfatizadas e passam a estar associadas à alfabetização, ou seja, ao processo de escolarização, o que também se expressa na evocação início-base, que traduz o sentido de preparação para a escola. É interessante verificar que, embora 
alfabetização tenha sido evocada por 102 pessoas, apenas 26 a indicaram como sendo uma das mais importantes entre as palavras evocadas. Assim, de todas as evocações situadas no primeiro quadrante, apenas criança e educação foram indicadas como mais importantes por pelo menos $50 \%$ dos sujeitos que as evocaram. Dessa forma, é possível que alfabetização, início e aprendizagem não façam parte do núcleo central, mas que sua presença no primeiro quadrante ofereça as nuances do sentido de educação, que é considerada função da pré-escola.

As palavras da primeira periferia referem-se às atividades desenvolvidas com e para a criança no espaço da pré-escola (brincar-brincadeiras e histórias-arte-jogos) e introduzem o adulto que se responsabiliza por ela e com quem ela interage nesse ambiente: o professor. Verifica-se, assim, que o início da escolaridade, expresso na aprendizagem da leitura e da escrita, como colocado no primeiro quadrante, é pensado em função da criança que aprende, o que requer que o professor organize atividades que considerem as características lúdicas dela. Isso pode sugerir a existência de um diferencial em relação ao ensino fundamental, que poderia definir a pré-escola como uma escola para crianças (pequenas). A preocupação em garantir a brincadeira é confirmada nas respostas à questão 14 do questionário, na qual $76 \%$ das acadêmicas selecionaram organizar brincadeiras como uma das tarefas da professora da pré-escola. Entretanto, apenas 54\% incluíram brincar entre essas tarefas, o que significa que, ao contrário da creche, a professora organiza as brincadeiras para as crianças e não com as crianças.

Entretanto, a ideia de "início" é ambígua, oscilando entre a preocupação em respeitar as características da criança (observadas na primeira periferia) e a aderência ao modelo de escola historicamente consolidado, expressa nas evocações localizadas na zona de contraste, no quadrante inferior esquerdo. Nesta, é delineado um cenário escolar, com as evocações cadeira-carteira-mesa e sala. Explicitamente, é atribuída uma função didática, de ensinar conhecimentos e as crianças são vistas como alunos com uma frequência bem maior (26 evocações para pré-escola contra 6 para creche).

Essa representação é confirmada nas respostas ao questionário, nas quais se verifica que a profissão mais próxima à de professora de 
pré-escola é a de professora de ensino fundamental (entre $42 \%$ na UFAL e $65 \%$ na Unesp) e que as tarefas mais importantes da professora são: avaliar as crianças (87\%), ensinar conteúdos escolares (87\%), participar de reuniões pedagógicas (85\%), ensinar a ler e a escrever (82\%), elaborar os planos de atividades (80\%), atender a crianças com necessidades especiais (78\%), elaborar e corrigir tarefas didáticas (77\%) e organizar reuniões de pais (73\%). Vemos, assim, que, ao pensarem nas tarefas da professora, as acadêmicas priorizam a sua identificação com o professor de ensino fundamental e só depois acrescentam as tarefas que se impõem em função da pouca idade das crianças.

Na segunda periferia, tal como em relação à creche, as três dimensões anteriormente definidas se tornam mais concretas. A imagem de criança se delineia com qualificadores como alegre-alegria e bagunça; surge uma criança sociável, com amigos e que realiza atividades. O professor também é qualificado como uma pessoa que dedica amor, atenção, paciência e responsabilidade. Quanto às funções da pré-escola, lazer-diversão, cuidado e alimentação já estavam presentes em creche, mas agora são acrescentados estudo, livros e disciplina, que, mais uma vez, chamam a atenção para a dimensão escolar da pré-escola. É interessante observar que a palavra desenvolvimento, que não tinha aparecido em creche, foi evocada em pré-escola.

Em síntese, a análise da associação livre mostra que a representação de pré-escola pode ser traduzida como o "início da escolaridade" ou da "vida escolar", com as características e funções desta, mas já (ou ainda) com algum diferencial em relação ao ensino fundamental, em função da idade das crianças atendidas. Esse diferencial é reconhecido nas respostas à questão 24 do questionário, na qual as acadêmicas atribuíram à professora de pré-escola algumas tarefas comuns à da professora de creche: transmitir valores (76\%), manter o contato com as famílias (76\%), zelar pela integridade física das crianças (66\%) e dar carinho (61\%), tarefas que se inserem na função de proteção e cuidado da educação infantil, mas, como mostram os resultados do questionário, não prevalecem sobre aquelas relacionadas à escolarização. 


\section{Considerações finais}

A trajetória paralela de creche e pré-escola produziu sentidos diferentes para essas instituições que se expressam em várias dimensões: natureza, objetivos e função; estrutura de funcionamento; clientela atendida; perfil e formação profissional; orientação pedagógica etc. Apesar da LDB/96 (BRASIL, 1996) redefinir creche e pré-escola diferenciando os dois tipos de atendimento apenas quanto à idade, 0 a 3 anos e 4 a 5 anos respectivamente, não é esse o sentido que prevalece no senso comum. Os dados desta pesquisa revelam que as estudantes do primeiro ano de Pedagogia veem essas instituições de maneiras bastante distintas, e essa diferenciação não se restringe à idade da criança atendida. Creche ainda é associada aos cuidados básicos da criança e pré-escola, à sua escolaridade e preparação ao ensino fundamental.

A comparação dos dados apresentados nos dois quadros indica que os estudantes atribuem aos dois tipos de instituições mais diferenças do que similaridades. No que tange à sua função, a recreação é o único ponto de intersecção de ambas as instituições, confirmando o que vem sendo construído ao longo da história. A subtração de início-base em creche e sua saliência em pré-escola confirmam a ideia de que a educação da criança pequena tem início na pré-escola, base para todo o processo de escolarização futura, e não na creche, oficialmente considerada a primeira subetapa da educação infantil. A ausência do atributo desenvolvimento em creche e sua pouca saliência em pré-escola também reflete o desconhecimento da principal função das etapas da educação infantil, de acordo com o artigo 29 da LDB, ou seja, "o desenvolvimento integral da criança até seis anos de idade, em seus aspectos físico, psicológico e social, complementando a ação da família e da comunidade". A ausência do atributo proteção em pré-escola pode indicar uma oposição ao sentido de benemerência a que foi associada à creche no passado, mas também implica ignorar um dos três pilares da Convenção dos Direitos Universais da Criança, que é sua proteção.

Quanto ao sujeito do contexto institucional, a criança é afirmada como o principal e inquestionável sujeito, que se compõe com bebê quando 
o contexto é a creche, ou com aluno quando o contexto é a pré-escola. A creche é um lugar da criança estando a ela associados a brincadeira e o brinquedo. A pré-escola é também um lugar de criança, acrescida do atributo aluno, sendo à criança-aluno associada a aprendizagem e a alfabetização. É uma criança que está em uma sala, iniciando um processo de ensino e que requer uma didática. Não é uma criança que chora, nem faz barulho. Por outro lado, tem amigos e está engajada em um processo de socialização.

A brincadeira é o único atributo referente aos elementos da ação pedagógica comum à creche e à pré-escola, sendo que da última está subtraído o brinquedo. Os elementos da ação pedagógica, tais como histórias-artes-jogos, estão presentes apenas na pré-escola. Parece que, conforme o sujeito deixa de ser criança e passa a ser aluno, fica sujeito a outras funções institucionais: desenvolvimento, conhecimento, alfabetização, aumentam as ações ditas "pedagógicas" e diminui a brincadeira, ou esta passa a ser um veículo para a aprendizagem de conteúdo.

Por outro lado, estão ausentes de creche os elementos da ação pedagógicas, tais como alfabetização, livros e histórias-artes-jogos, assim como as dimensões relacionais que envolvem a cultura de pares, como ter amigos e se engajar no processo de socialização. Talvez prevaleça a ideia de que as competências para a relação entre pares aconteçam mais tarde ou que em creche essa importante dimensão não seja considerada.

A princípio, na perspectiva de uma abordagem integrada de educação infantil, creche, comparativamente à pré-escola, apresenta indicadores que mais se aproximariam de uma visão que associa e integra a educação e o cuidado da criança. Entretanto, é curioso e preocupante que os elementos de uma pedagogia para a criança pequena, com os atributos mencionados, estejam ausentes em creche.

Podemos antecipar que a ideia de creche e pré-escola como subetapas da educação infantil, ambas destinadas ao desenvolvimento integral da criança em todos os seus aspectos e voltadas de forma indissociável às funções de cuidar e educar, não foi assimilada pelas estudantes em questão. Essa constatação confirma a ideia de que a simples legalização da educação infantil não é suficiente para vencer as inconsistências do passado. 
Faz-se necessária uma mudança de paradigma para a qual a formação inicial tem um papel fundamental. Resta saber se ela está efetivamente cumprindo esse papel. A continuidade deste estudo, com a realização de entrevistas com os mesmos sujeitos no fim do curso, permitirá responder a essa questão e apontar os elementos que contribuem para a mudança e para a permanência da RS ao longo do curso.

\section{Agradecimentos}

Ao CNPq, pelo apoio financeiro; aos demais membros da equipe de trabalho da UFAL, especialmente Dayana Flávia Bulhões dos Santos (bolsista de Iniciação Científica CNPq); às colegas Daniela Freire Andrade, da UFMT, Célia Maria Guimarães e Cláudia Cristina G. Piffer da Unesp Presidente Prudente, e Sílvia Adriana Rodrigues, da UFMS - Corumbá.

\section{Referências}

ABRIC, J. A abordagem estrutural das representações sociais. In: MOREIRA, A. S. P.; OLIVEIRA, D. C. (Org.). Estudos interdisciplinares de representação social. 2. ed. Goiânia: Ed. AB, 2000. p. 27-38.

ANDRADE, D. B. da S. F.; SANTOS, M. F. dos. O outro do adulto e do professor: representações sociais sobre criança, segundo licenciados de Pedagogia da UFMT. Nuances: Estudos sobre Educação, v. 16, n. 17, p. 105-117, jan./dez. 2009.

BRASIL. Constituição (1988). Constituição: República Federativa do Brasil. Brasília, DF: Senado Federal, 1988.

BRASIL. Lei n. 9.394/96, de 20 de dezembro de 1996. Estabelece as diretrizes e bases da educação nacional. Diário Oficial [da] República Federativa do Brasil, Poder Legislativo, Brasília, DF, 23 dez. 1996. p. 27833. Disponível em: <http://www6.senado. gov.br/legislacao/ListaTextoIntegral.action?id=75723>. Acesso em: 23 jul. 2009. 
CORDEIRO, M. H.; HADDAD, L. A especificidade do trabalho da professora de educação infantil: implicações teóricas e metodológicas para a pesquisa em representações sociais. 2011. No prelo.

DEMATHÉ, T. M. Representação social das professoras de educação infantil de Corupá sobre infância. 2007. 97 f. Dissertação (Mestrado em Educação) Universidade do Vale do Itajaí, Itajaí, 2007.

DEMATHÉ, T. M.; CORDEIRO, M. H. Representações sociais sobre infância: um estudo com pais e educadoras da Educação Infantil. Nuances: Estudos sobre Educação, v. 16, n. 17, p. 119-133, jan./dez. 2009.

FERNANDES, M. Z. Representação social do bom professor da educação infantil. 2004. 138 f. Dissertação (Mestrado em Educação) - Universidade do Vale do Itajaí, Itajaí, 2004.

HADDAD, L. A ecologia do atendimento infantil: construindo um modelo de sistema integrado de cuidado e educação. 1997. 327 f. Tese (Doutorado em Educação) - Universidade de São Paulo, São Paulo, 1997.

HADDAD, L. An Integrated Approach to Early Childhood Education and Care. São Paulo: EDUCERE, 2002. Disponível em: <http://www.childcarecanada. org/pubs/op16/op16.pdf>. Acesso em: 23 jul. 2009.

HADDAD, L. Políticas integradas de educação e cuidado infantil: desafios, possibilidades e armadilhas. Cadernos de Pesquisa, v. 36, n. 129, p. 519-546, set./ dez., 2006.

MENIN, M. S. de S. O aspecto normativo das representações sociais: comparando concepções. Revista de Educação Pública, v. 16, n. 30, p. 121-135, jan./abr. 2007.

MOSCOVICI, S. Representações sociais: investigações em psicologia social. 3. ed. Petrópolis: Vozes, 2005.

ONGARI, B.; MOLINA, P. A educadora de creche: construindo suas identidades. São Paulo: Cortez, 2003. 
PACHECO, A. A representação social de brincar e aprender para acadêmicas do curso de Pedagogia: habilitação em educação infantil e séries iniciais do ensino fundamental. 2005. 122 f. Dissertação (Mestrado em Educação) Universidade do Vale do Itajaí, Itajaí, 2005.

SALES, S. A. da C. "Falou, ta falado!” As representações sociais docentes sobre infância, criança, educação infantil e papel do professor. 2007. 184 f. Dissertação (Mestrado em Educação) - Universidade Federal do Ceará, Fortaleza, 2007.

VERGÈS, P. Ensemble de programmes permettant lanalyse des evocations: Manuel version 2.00. Aix-en-Provence: Laboratoire Méditerranée en Sociologie, 2000.

Recebido: 25/08/2010

Received: 08/25/2010

Aprovado: 30/09/2010

Approved: 09/30/2010 